\title{
Effects of Second-Order Hydrodynamics on the Dynamic Responses and Fatigue Damage of a 15 MW Floating Offshore Wind Turbine
}

\author{
Xuan Mei ${ }^{1}$ and Min Xiong ${ }^{2, *}$ \\ 1 Shanghai International Port Group Co., Ltd., Shanghai 200080, China; xuanmei2@gmail.com \\ 2 Department of Geotechnical Engineering, College of Civil Engineering, Tongji University, \\ Shanghai 200092, China \\ * Correspondence: 1310298@tongji.edu.cn
}

check for

updates

Citation: Mei, X.; Xiong, M. Effects of Second-Order Hydrodynamics on the Dynamic Responses and Fatigue Damage of a 15 MW Floating

Offshore Wind Turbine. J. Mar. Sci. Eng. 2021, 9, 1232. https://doi.org/ $10.3390 /$ jmse9111232

Academic Editors: Zhen Liu,

Yaling Chen, Yang Yang and

Siming Zheng

Received: 6 October 2021

Accepted: 3 November 2021

Published: 7 November 2021

Publisher's Note: MDPI stays neutral with regard to jurisdictional claims in published maps and institutional affiliations.

Copyright: (c) 2021 by the authors. Licensee MDPI, Basel, Switzerland. This article is an open access article distributed under the terms and conditions of the Creative Commons Attribution (CC BY) license (https:/ / creativecommons.org/licenses/by/ $4.0 /)$.

\begin{abstract}
In order to investigate the effects of second-order hydrodynamic loads on a $15 \mathrm{MW}$ floating offshore wind turbine (FOWT), this study employs a tool that integrates AQWA and OpenFAST to conduct fully coupled simulations of the FOWT subjected to wind and wave loadings. The load cases covering normal and extreme conditions are defined based on the met-ocean data observed at a specific site. The results indicate that the second-order wave excitations activate the surge mode of the platform. As a result, the surge motion is increased for each of the examined load case. In addition, the pitch, heave, and yaw motions are underestimated when neglecting the second-order hydrodynamics under the extreme condition. First-order wave excitation is the major contributor to the tower-base bending moments. The fatigue damage of the tower-base under the extreme condition is underestimated by $57.1 \%$ if the effect of second-order hydrodynamics is ignored. In addition, the accumulative fatigue damage over 25 years at the tower-base is overestimated by $16.92 \%$. Therefore, it is suggested to consider the effects of second-order wave excitations of the floating platform for the design of the tower to reduce the cost of the FOWT.
\end{abstract}

Keywords: second-order hydrodynamics; dynamic responses; fatigue damage; 15 MW floating offshore wind turbine

\section{Introduction}

The wind energy sector is attracting attention in a bid to accelerate energy transfer in a low-carbon consuming manner. In 2020, the global new wind power installations increased by $90 \mathrm{GW}$, equivalent to a $53 \%$ growth compared to 2019 [1]. Wind energy is expected to play a significant role in the road to net zero by generating more than $25 \%$ electricity in 2050 with a large contribution of offshore wind [2]. As a result of the saturation of wind energy utilization in shallow water-depth areas in the near future, the wind resource in deep-sea areas will become an alternative renewable energy of great potential due to its higher energy density and smaller fluctuation. The floating technology is the best option for wind energy development in deep water-depth areas. Thus, floating offshore wind turbines (FOWTs) have become a research hotspot in recent years.

FOWT can be classified into four major categories from the aspect of how to achieve hydrostatic stability, as shown in Figure 1. One is the spar type that achieves roll/pitch stability by its deeply installed ballast. The Hywind spar developed by Equinor is the first successfully commercialized floating wind concept and it has been applied in several practicing projects, including the Scotland floating wind farm with a total capacity of $30 \mathrm{MW}$. The second category, the barge type, is stabilized by the buoyancy provided by its large water plane area. The Ideol concept developed by the BW is a successful commercial product that is used in multiple floating wind projects in France and Japan. The tension leg platform (TLP) is another FOWT category that is stabilized by taut mooring 
lines. Due to the high cost and difficulty in installation, this concept has not been applied in a demo project yet. The other category is semi-submersible, mainly stabilized by buoyancy. Since the semisubmersible type is applicable for a variety of water depths and has a good hydrodynamic performance, it is a very promising technology for floating wind utilization [3].

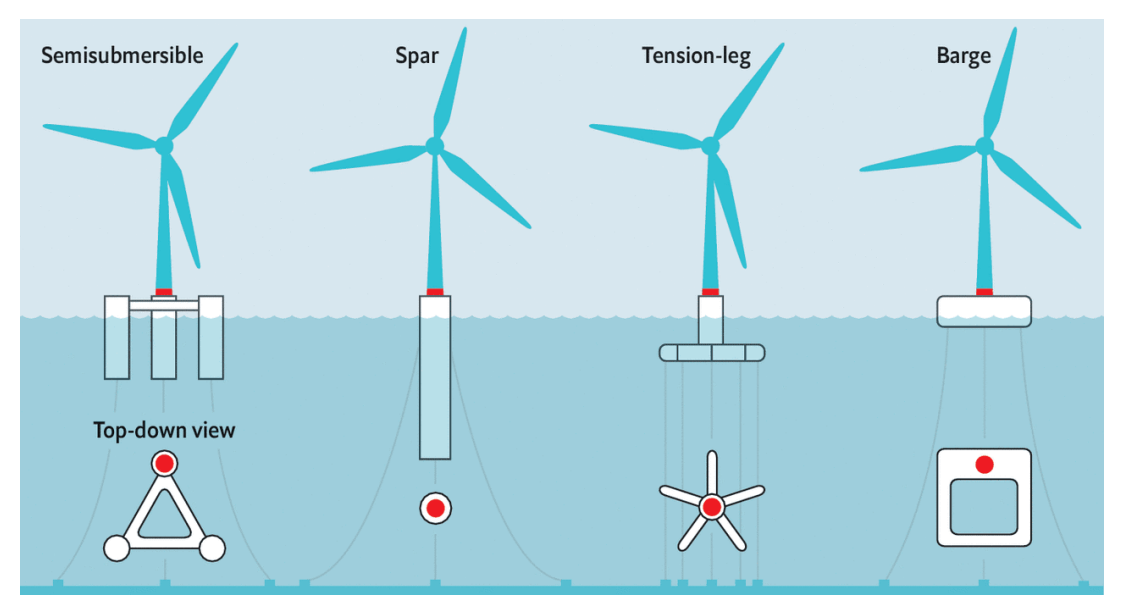

Figure 1. Floating wind platform categories.

The semisubmersible type wind turbine platform has attracted a lot of attention, thanks to its good hydrodynamic behavior and wide operation range of water depth. In the past decades, numerous studies have been carried out to assess the hydrodynamic and fatigue problems associated with semisubmersibles. In the Offshore Code Comparison Collaboration Continuation (OC4) project, the DeepCwind concept proposed by UMaine was adopted as the case study to validate commonly-used numerical tools [4]. Robertson et al. [5] conducted a series of wave tank tests of the scale models, including the semisubmersible. The platform motions and loads of the test model were compared to the relevant results obtained using FAST. Masciola et al. [6] investigated the dynamic effects of mooring system on the responses of the DeepCwind FOWT using FAST that was integrated with OrcaFlex. It was found that the quasi-static catenary method underestimated the peak tension in the mooring lines. Hall et al. [7] employed FAST to conduct fully coupled simulation of the semisubmersible FOWT subjected to wind-wave combined loads. The mooring lines were modeled using the quasi-static catenary and lumped-mass methods, respectively. The numerical results were validated through 1:50-scale experimental data. It was found that the lumped-mass method was able to capture the mooring dynamic effects as confirmed by the comparisons with good agreements. The tests conducted in the University of Marine were also used by Coulling et al. [8] to validate the aero-hydro-servo-elastic responses of the $5 \mathrm{MW}$ wind turbine installed on the DeepCwind platform. Tran et al. [9] adopted the computational fluid dynamic (CFD) method to examine the viscous effects of the DeepCwind platform. The CFD analysis result was compared against the numerical simulation results from AQWA regarding the mooring tensions and platform motions. Kim et al. [10] investigated the global performance of the DeepCwind concept subjected to random wind and waves using CHARM3D-FAST. The second-order diffraction/radiation potentials were considered when performing the frequency domain analysis. The numerical results were validated by comparing them to model tests and a good agreement in the response spectrum was obtained. Huang et al. [11] developed a solver within OpenFOAM for carrying out hydrodynamic analysis of the DeepCwind platform. The high-fidelity analysis found that the platform motions were sensitive to the low-frequency waves. Liu et al. [12] conducted a study to assess the wave-resistance ability of the DeepCwind prototype with different external columns. The pitch and heave motions were insensitive to the amount of offset columns, while the natural period of surge was significantly influenced. Consequently, the surge motion was reduced when the number of columns increased. 
Lee et al. [13] carried out a fatigue study on the FOWT supported by the DeepCwind platform based on hydrodynamic-structure interaction analysis. The cumulative fatigue damage of the structure was predicted in accordance with the DNV-RP-C203 standard. Netzband et al. [14] investigated the platform motions of the 5 MW FOWT supported by the DeepCwind concept. An aero-hydrodynamic analysis was performed to investigate the wake development and the influence on blade loads. Ishihara et al. [15] predicted the dynamic responses of a 5 MW FOWT mounted on a semisubmersible using a fully coupled simulation tool. The frequency-dependent coefficients due to the diffraction effects were calculated and applied to calculate the hydrodynamic forces due to irregular waves. The numerical analysis was compared to the water tank tests for validating the coupled method in carrying out simulations of FOWTs.

It is noted that most of the above studies focused on the dynamic motions of the platform subjected to the first-order hydrodynamic loads. The second-order hydrodynamic effects were not well evaluated. Bayati et al. [16] assessed the effects of second-order hydrodynamics on the DeepCwind FOWT. The structural loads and responses due to the second-order hydrodynamics were compared to those induced by the first-order hydrodynamics in the frequency domain. Afterwards, the second-order hydrodynamic forces and its triggered responses were compared to those caused by aerodynamic loads in FAST. Roald et al. [17] adopted the commonly-used method in the oil and gas industry to investigate the effects of second-order hydrodynamics on 5 MW FOWTs. The sum- and difference-quadratic transfer functions (QTFs) matrices were calculated in WAMIT and applied in the open source tool, FAST. The effects of second-order hydrodynamic forces on platform motions were analyzed and compared to the aerodynamic effects. Zhou et al. [18] performed a sensitivity analysis on the design parameters of the semisubmersible platform regarding the manufacturing, structural, and hydrodynamic aspects. The effects of geometrical design parameters, including the draft, column spacing, and radius on the second-order hydrodynamics were analyzed. Jurado et al. [19] aimed to study the slowdrift motions of a 5 MW FOWT. The slow-drift forces were calculated using the full QTFs. It was found that neglecting first-order motion effects would lead to an underestimation of the surge responses in severe sea states. Zhang et al. [20] analyzed the contribution of second-order hydrodynamics to platform motions and fatigue damage of three $5 \mathrm{MW}$ FOWTs supported by different semisubmersibles. The second-order hydrodynamic forces were computed using the Newman's approximation and the full QTF matrices, respectively. It was found that the second-order difference loads would trigger the resonance of platform pitch motion, leading to a large fatigue damage. In addition, the QTF method is relatively accurate in predicting the responses of the semisubmersible FOWTs. Xu et al. [21] employed the SIMO-Riflex-AeroDyn tool to conduct fully coupled simulations of semisubmersible FOWT operating in different water depth seas. The second-order hydrodynamic forces were examined using Newman's approximation and full QTF, respectively. Zhao et al. [22] investigated the effects of second-order hydrodynamic loads on the dynamic responses and fatigue of $10 \mathrm{MW}$ and $5 \mathrm{MW}$ semisubmersible FOWTs. The full QTF matrices due to sum- and difference-frequency were calculated using a frequency domain analysis tool and then imported into FAST for the time domain analysis. It was found that the low-frequency responses will be underestimated if ignoring the second-order difference-frequency wave loads. The sum-frequency hydrodynamic loads had an impact on the structural dynamics of the 10 MW FOWT. It is noted that the fatigue damage of the 10 MW FOWT was more affected by the second-order hydrodynamics. Chuang et al. [23] assessed influence of second-order hydrodynamics on coupled responses of a 5 MW FOWT supported by the DeepCwind platform. The SIMA and FAST were, respectively, used to conduct the coupled simulations considering the mean drift, slow-drift excitations those were computed based on the QTF obtained from the frequency-domain analysis. It was found that the slow-drift forces had a larger effect than the mean drift force. In addition, the fairlead tension and tower base load were increased by the second-order wave excitation. Simos et al. [24] investigated the slow-drift effects on a 1.5 MW FOWT's dynamic responses using a frequency 
domain method and model tests. It was found that the second-order responses were underestimated by the Newman's approximation method when comparing to the model test results. Cao et al. [25] adopted FAST to analyze the second-order hydrodynamics' effects on the dynamic response of a 10 MW FOWT. The QTF matrices and Newman's approximation were both employed to examine the second-order hydrodynamics. The study found that the second-order forces computed using the QTF lead to a high-frequency response in the tower-top force spectrum. Li et al. [26] investigated the effects of the second-order difference-frequency wave excitation on the responses of a FOW under survival conditions. It found that the prediction of tension forces was smaller when neglecting the second-order hydrodynamics. Moreover, the motions were significantly affected by the second-order wave forces.

However, most of the above studies were focusing on 5 MW FOWTs. The FOWTs investigated by the above studies have a maximum capacity of $10 \mathrm{MW}$. It is noted that larger wind turbines have a larger potential in reducing the cost of energy. In addition, the larger wind turbines require a larger size platform, subjecting more complex hydrodynamics. The second-order hydrodynamics may have significant influence on the responses and fatigue loads of the tower-base and mooring lines. Therefore, it is imperative to assess the effects of second-order hydrodynamics on 15 MW FOWTs.

This paper aims to investigate the effects of second-order hydrodynamics on a $15 \mathrm{MW}$ FOWT supported by a semisubmersible type platform. The fully coupled simulation tool F2A that integrates FAST and AQWA is used to examine the aero-hydro-servo-elastic responses of the FOWT under wind-wave combined loadings. The full QTF matrices corresponding to the sum-and difference-frequency are calculated within AQWA. The load cases are defined in accordance with the met-ocean data observed in the east coast of the US. The influence of second-order hydrodynamics on the platform motions, tower-base loads, and mooring tensions is analyzed for the normal power production and survival environmental conditions. The fatigue damage of the tower is then evaluated following the S-N curve method described in the DNV standard to quantitatively analyze the effect of the second-order hydrodynamics.

\section{Model Description}

\subsection{The IEA $15 \mathrm{MW}$ Wind Turbine}

In order to active collaborations between industrial and academic communities regarding the development of next-generation large offshore wind turbine, a $15 \mathrm{MW}$ reference wind turbine was designed by the National Renewable Energy Laboratory (NREL) and Technical University of Denmark (DTU) through a wind task that was sponsored by the International Energy Agency (IEA). The so-called IEA 15 MW reference wind turbine serves as an open source model with detailed design parameters for benchmark studies to explore new technologies. The drivetrain system is direct-drive type to avoid the gearbox design issue. The rotor diameter and blade length are $240 \mathrm{~m}$ and $117 \mathrm{~m}$, respectively. The maximum tip speed is designed to under the limit of $95 \mathrm{~m} / \mathrm{s}$. The wind turbine is expected to achieve the maximum power coefficient of 0.489 under the rated wind speed of $10.59 \mathrm{~m} / \mathrm{s}$ and the rated rotor speed of $7.56 \mathrm{~m} / \mathrm{s}$. Table 1 lists the main parameters of the IEA $15 \mathrm{MW}$ reference wind turbine. 
Table 1. Main design parameters of the IEA $15 \mathrm{MW}$ reference wind turbine.

\begin{tabular}{cccc}
\hline Parameters/Unit & Value & Parameters/Unit & Value \\
\hline Rated power/(MW) & 15 & Rotor diameter $(\mathrm{m})$ & 240 \\
Turbine class $/(-)$ & IEC Class 1B & Hub diameter $(\mathrm{m})$ & 7.94 \\
Cut-in wind speed (m/s) & 3 & Hub overhang $(\mathrm{m})$ & 11.35 \\
Cut-out wind speed (m/s) & 25 & Shaft tilt angle $(\mathrm{deg})$ & 6 \\
Rated wind speed (m/s) & 10.59 & Rotor precone $(\mathrm{deg})$ & -4 \\
Minimum rotor speed (rpm) & 5.0 & Blade prebend $(\mathrm{m})$ & 4 \\
Maximum rotor speed (rpm) & 7.56 & Blade mass $(\mathrm{kg})$ & 65,000 \\
Maximum tip speed (m/s) & 95 & Rotor-nacelle mass $(\mathrm{kg})$ & $1,017,000$ \\
\hline
\end{tabular}

\subsection{The ActiveFloat Platform}

A semi-submersible concreate platform with one central and three offset vertical columns is developed under the collaboration of COBRA and ESTEYCO through the CoreWind project to accommodate the IEA $15 \mathrm{MW}$ reference wind turbine. The semisubmersible platform, namely ActiveFloat, is made of reinforced concrete. The three offset vertical columns are connected to the central shaft through pontoons that provide structural strength and heave damping. Each offset column has a heave plate with a larger diameter. The design operation water depth is $200 \mathrm{~m}$. Figure 2 presents a schematic diagram of the ActiveFloat platform.
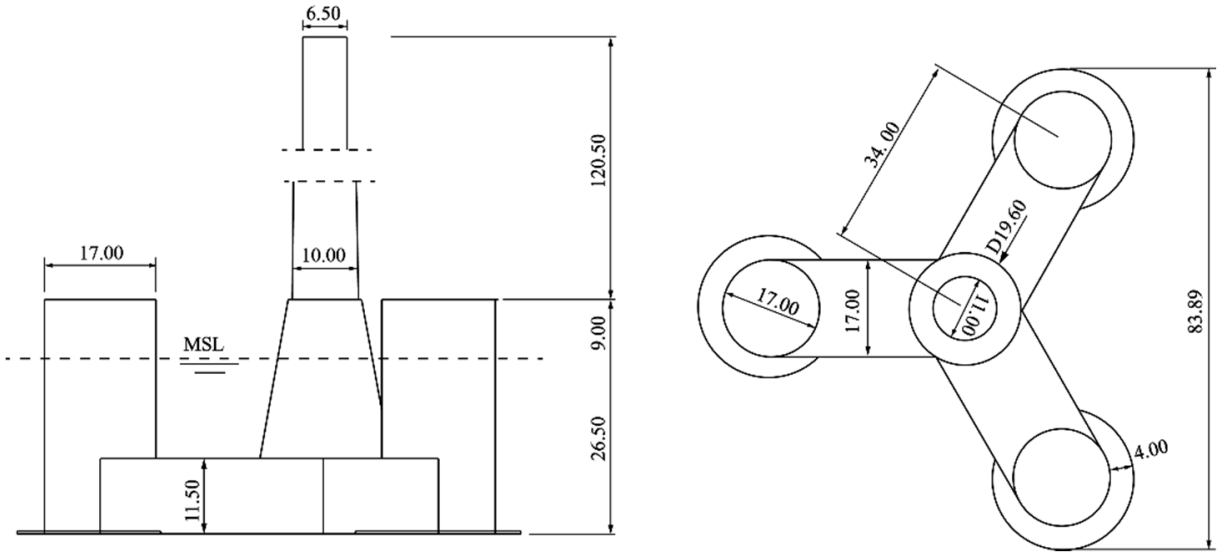

Figure 2. Geometry of the ActiveFloat platform.

The design displacement of the AcitiveFloat platform is $36,431.22 \mathrm{~m}^{3}$. The operation draught and transportation draft are $26.5 \mathrm{~m}$ and $11 \sim 13 \mathrm{~m}$, respectively. The vertical coordinates of the center of mass and center of buoyancy are $-11.09 \mathrm{~m}$ and $-15.83 \mathrm{~m}$. The platform mass including the ballast is $34,387,200 \mathrm{~kg}$. The inertias of mass are $1.57 \times 10^{10} \mathrm{~kg} \cdot \mathrm{m}^{2}$, $1.57 \times 10^{10} \mathrm{~kg} \cdot \mathrm{m}^{2}$ and $2.58 \times 10^{10} \mathrm{~kg} \cdot \mathrm{m}^{2}$, respectively, for the roll, pitch, and yaw directions. Table 2 presents the key parameters of the ActiveFloat platform.

Table 2. Key design parameters of the ActiveFloat platform.

\begin{tabular}{cccc}
\hline Parameters/Unit & Value & Parameters/Unit & Value \\
\hline Operation draught $/(\mathrm{m})$ & 15 & Displacement $\left(\mathrm{m}^{3}\right)$ & $36,431.22$ \\
Transportation draught $/(\mathrm{m})$ & IEC Class 1B & Platform mass $(\mathrm{kg})$ & $34,387,200$ \\
KG $(\mathrm{m})$ & 15.41 & Ixx $\left(\mathrm{kg} \cdot \mathrm{m}^{2}\right)$ & $1.57 \times 10^{10}$ \\
KB $(\mathrm{m})$ & 10.67 & Iyy $\left(\mathrm{kg} \cdot \mathrm{m}^{2}\right)$ & $1.57 \times 10^{10}$ \\
GM $(\mathrm{m})$ & 6.41 & Izz $\left(\mathrm{kg} \cdot \mathrm{m}^{2}\right)$ & $2.58 \times 10^{10}$ \\
\hline
\end{tabular}

In order to accommodate the IEA $15 \mathrm{MW}$ wind turbine following a series of constrains, the tower is re-designed. The new tower has a length of $120.5 \mathrm{~m}$ with a top diameter of 
$6.5 \mathrm{~m}$ and a base diameter of $10 \mathrm{~m}$. The tower is placed on the top surface of the platform that is $9 \mathrm{~m}$ above the mean sea level (MSL), meaning that the tower top is $129.5 \mathrm{~m}$ above the MSL.

The mooring system consists of three catenary cables. The upstretched length and diameter of each mooring line are $614 \mathrm{~m}$ and $0.16 \mathrm{~m}$, respectively. The mass density and equivalent axial stiffness of the mooring line are $561.2 \mathrm{~kg} / \mathrm{m}$ and $2.3 \mathrm{GN}$, respectively. The mooring system will provide a considerable stiffness to constrain the surge motion of the platform below $15 \mathrm{~m}$. Table 3 gives the coordinates of the fairleads and anchors of the mooring lines. Figure 3 presents a schematic diagram of the IEA 15 MW reference wind turbine mounted on the ActiveFloat platform.

Table 3. Mooring line coordinates (unit: $\mathrm{m}$ ).

\begin{tabular}{ccccccc}
\hline Line \# & \multicolumn{3}{c}{ Fairleads } & \multicolumn{3}{c}{ Anchors } \\
\hline & $x$ & $y$ & $z$ & $X$ & $y$ & $z$ \\
1 & -42.50 & 0.00 & -15.00 & -600.00 & 0.00 & -200.00 \\
2 & 21.25 & -36.81 & -15.00 & 300.00 & -519.62 & -200.00 \\
3 & 21.25 & 36.81 & -15.00 & 300.00 & 519.62 & -200.00 \\
\hline
\end{tabular}

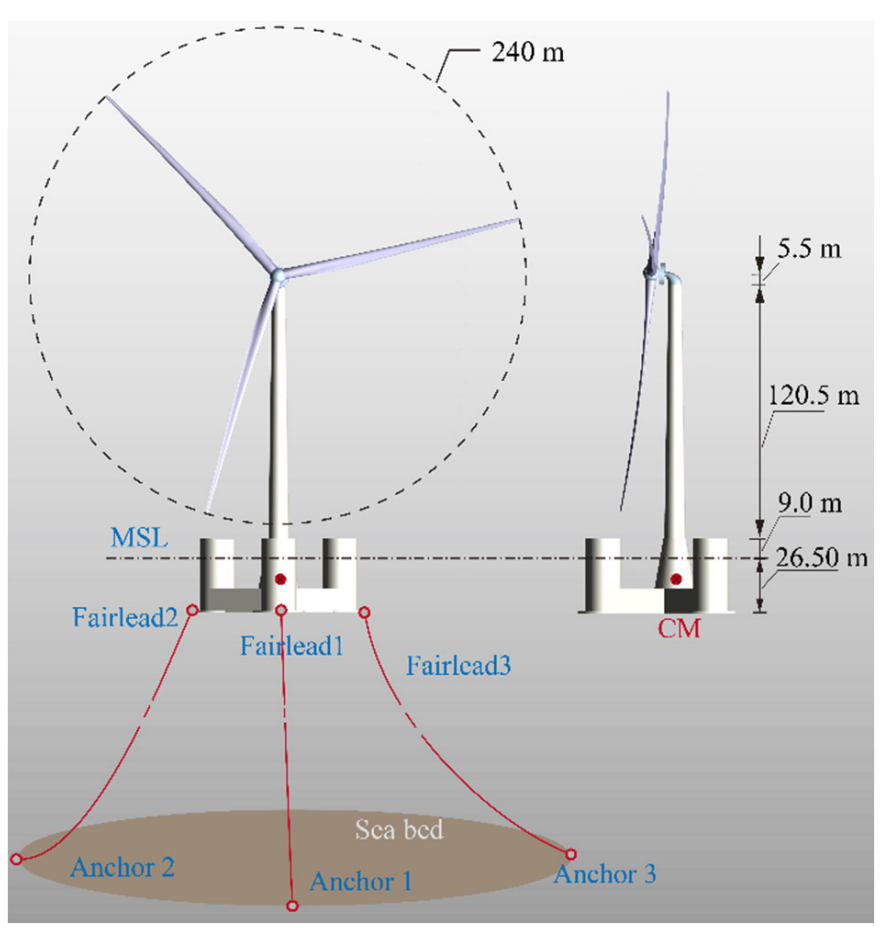

Figure 3. Schematic diagram of the IEA $15 \mathrm{MW}$ wind turbine on the ActiveFloat platform.

\section{Fully Coupled Analysis Methodology}

\subsection{Description of the Aero-Servo-Elastic Modeling in F2A}

This study intends to employ a powerful tool, namely F2A, to conduct the fully coupled simulations. F2A was developed by Yang et al. [27,28] based on the open source tool FAST and AQWA that is the hydrodynamic analysis component of ANSYS software package. In F2A, FAST is used to predict the aero-servo-elastic responses of the upper structures including the rotor, nacelle, and tower of the FOWT. The dynamics of the subsystem consisting of the platform and mooring system are examined in AQWA. The interaction between upper structures and the subsystem is implemented by a user-force dynamic link library (DLL) that links FAST subroutines when performing an analysis in AQWA. The platform displacements, velocities, and accelerations computed in AQWA will be transferred into the FAST subroutines through the DLL in each time step of the 
analysis. The kinematics of the upper structures will be updated accordingly. Afterwards, the dynamic responses of the rotor and tower are predicted. The tower-base loads obtained by FAST are then fed back into AQWA through the DLL for the determination of platform responses.

The aerodynamic loads acting on the rotor are predicted using the generalized dynamic wake model combined with the blade-element momentum theory (BEMT). More specifically, the dynamic axial induction velocity distribution over the rotor disk is obtained by solving the Laplace equation of pressure established based on the potential theory. The tangential induction velocity is obtained using the BEMT. The lift and drag coefficients are called by looking up the aerodynamic performance tables of each blade sectional airfoil to calculate the aerodynamic loads on each blade using the equations will be then calculated through the following equations [29]:

$$
\begin{gathered}
T=\frac{1}{2} \rho \int_{r_{h u b}}^{R} W_{r}^{2} c_{r}\left(C_{l} \cos \phi+C_{d} \sin \phi\right) \mathrm{d} r \\
Q=\frac{1}{2} \rho \int_{r_{h u b}}^{R} W_{r}^{2} c_{r}\left(C_{l} \sin \phi-C_{d} \cos \phi\right) r \mathrm{~d} r
\end{gathered}
$$

where $T$ is the thrust and $Q$ is the torque produced by the blade. $\rho$ is the density of wind; $C_{l}$ and $C_{d}$ are, respectively, the lift and drag coefficients of blade sectional airfoil. $r_{h u b}$ and $R$ are the hub radius and rotor radius, respectively. $c_{r}$ is the chord length of the blade element; $r$ and $\mathrm{d} r$ are the local radius and length of the blade element, respectively; $\phi$ is the relative inflow angle of the blade section. $W_{r}$ denotes the relative inflow speed.

The elastic deformation of the blades and tower is examined using the assumed-modal method. The first- and second-order flapwise modes and first-order edgewise mode are considered. While the first- and second-order fore-aft and side-side modes of the tower are taken into account. The elastic deformation of the blades and tower is calculated based on the potential energy and the generalized coordinate.

The variable-pitch and variable-speed control scheme is used to adjust the blade pitch angle and rotor speed for normal power production through a Bladed-style DLL. The generator torque is controlled to achieve a target rotor speed according to the current aerodynamic torque as shown in Equation (3).

$$
Q_{\text {aero }}-Q_{\text {gen }}=I_{\text {drive }} \Delta \dot{\Omega}
$$

where $Q_{a e r o}$ and $Q_{g e n}$ are respectively the aerodynamic torque and target generator torque; $I_{\text {drive }}$ is the inertia of the drivetrain system; $\Delta \dot{\Omega}$ is the derivative of generator speed perturbation.

The pitch controller will take over when the wind speed is larger than the rated speed through a proportional-integral scheme as given in Equation (4).

$$
\Delta \theta=K_{P} \Delta \Omega+K_{I} \int_{0}^{t} \Delta \Omega \mathrm{d} t
$$

where $\Delta \theta$ is the pitch angle perturbation. $K_{P}$ and $K_{I}$ are, respectively, the proportional and integral gains.

\subsection{Hydrodynamics in AQWA}

The equation of motion of the platform is solved within AQWA considering the aerodynamic loads, hydrodynamic loads and mooring restoring forces. For an arbitrary floating platform modeled in AQWA, the governing equation of the platform motions can be derived as [25]:

$$
\left[\mathrm{M}+A_{\infty}\right] \ddot{\mathrm{X}}(t)+\int_{0}^{t} \mathrm{~K}(\tau) \dot{\mathrm{X}}(t-\tau) \mathrm{d} \tau+\mathrm{CX}(t)=\mathrm{F}_{w 1}+\mathrm{F}_{w 2}+\mathrm{F}_{\text {aero }}+\mathrm{F}_{\text {moor }}
$$


where $\mathrm{X}, \dot{\mathrm{X}}$ and $\ddot{\mathrm{X}}$ are, respectively, the vectors of displacement, velocity and acceleration; $\mathrm{M}$ and $A_{\infty}$ are, respectively, the inertial mass and added mass matrices. $\mathrm{F}_{w 1}$ and $\mathrm{F}_{w 2}$ are, respectively, the first- and second-order wave excitation forces; $\mathrm{F}_{\text {aero }}$ and $\mathrm{F}_{\text {moor }}$ are the aerodynamic and mooring restoring force vectors. $\mathrm{C}$ is the hydrostatic restoring matrix. $K(\tau)$ denotes the retardation function and $\tau$ is the retardation time. $K(\tau)$ is represented by [30]:

$$
\mathrm{K}(\tau)=\frac{2}{\pi} \int_{0}^{+\infty} \mathrm{B}(\omega) \cos \omega \tau \mathrm{d} \omega
$$

where $\mathrm{B}(\omega)$ is the potential damping matrix, denoting the memory effect caused by the platform motions.

The time-dependent first- and second-order wave excitation forces, $\mathrm{F}_{w 1}$ and $\mathrm{F}_{w 2}$, can be represented as [31]:

$$
\begin{gathered}
\mathrm{F}_{w 1}=\frac{1}{2 \pi} \int_{-\infty}^{+\infty} \mathrm{h}_{1}(\tau) \zeta(t-\tau) \mathrm{d} \tau \\
\mathrm{F}_{w 2}=\frac{1}{4 \pi^{2}} \int_{-\infty}^{+\infty} \int_{-\infty}^{+\infty} \mathrm{h}_{2}\left(\tau_{1}, \tau_{2}\right) \zeta\left(t-\tau_{1}\right) \zeta\left(t-\tau_{2}\right) \mathrm{d} \tau_{1} \mathrm{~d} \tau_{2}
\end{gathered}
$$

where $\zeta$ is the complex Fourier component of sea surface elevation. $h_{1}(\tau)$ is the linear impulse response function of wave force. It is only related to one time instant. $h_{2}\left(\tau_{1}, \tau_{2}\right)$ is the second-order impulse response function of wave force, which is a function of two time instants. These two impulse response functions are assumed to be smooth. The Fourier transforms of these two functions can be denoted as:

$$
\begin{gathered}
\mathrm{h}_{1}(\tau)=\frac{1}{2 \pi} \int_{-\infty}^{+\infty} \mathrm{H}_{1}(\omega) e^{i \omega \tau} \mathrm{d} \omega \\
\mathrm{h}_{2}\left(\tau_{1}, \tau_{2}\right)=\frac{1}{4 \pi^{2}} \int_{-\infty}^{+\infty} \int_{-\infty}^{+\infty} \mathrm{H}_{2}\left(\omega_{1}, \omega_{2}\right) e^{i\left(\omega_{1} \tau_{1}+\omega_{2} \tau_{2}\right)} \mathrm{d} \omega_{1} \mathrm{~d} \omega_{2}
\end{gathered}
$$

where $\mathrm{H}_{1}(\omega)$ and $\mathrm{H}_{2}\left(\omega_{1}, \omega_{2}\right)$ are the first- and second-order wave excitation transfer functions those are predicted in a frequency-domain analysis. $\omega$ is the wave frequency; $\omega_{1}$ and $\omega_{2}$ are the wave frequencies of the two wave components contributing to the second-order wave forces.

The second-order wave excitation force is obtained through direct pressure integration along the instantaneous wet surface of the platform, which is contributed by five terms [32]: (i) relative wave height; (ii) rotational effect of the first-order force; (iii) the coupling of the first-order pressure gradient and first-order motion; (iv) pressure variation caused by the square term of the fluid velocity; and (v) influence of the second-order velocity potential. These five terms can be calculated in the frequency domain by solving the boundary-value problem [33]. By considering the mean free surface and platform surface in solving the second-order boundary-value problem, the second-order force can also be denoted by synchronous and asynchronous transfer functions as follows:

$$
\begin{aligned}
\mathrm{F}_{w 2} & =\sum_{m=1}^{N} \sum_{n=1}^{N} \frac{1}{2} \zeta_{m} \zeta_{n} \bar{P}_{m n} \cos \left\{\left(\omega_{m}+\omega_{n}\right) t+\left(\varepsilon_{m}+\varepsilon_{n}\right)\right\}+\sum_{m=1}^{N} \sum_{n=1}^{N} \frac{1}{2} \zeta_{m} \zeta_{n} \bar{Q}_{m n} \sin \left\{\left(\omega_{m}+\omega_{n}\right) t+\left(\varepsilon_{m}+\varepsilon_{n}\right)\right\} \\
& +\sum_{m=1}^{N} \sum_{n=1}^{N} \frac{1}{2} \zeta_{m} \zeta_{n} P_{m n} \cos \left\{\left(\omega_{m}-\omega_{n}\right) t+\left(\varepsilon_{m}-\varepsilon_{n}\right)\right\}+\sum_{m=1}^{N} \sum_{n=1}^{N} \frac{1}{2} \zeta_{m} \zeta_{n} Q_{m n} \sin \left\{\left(\omega_{m}-\omega_{n}\right) t+\left(\varepsilon_{m}-\varepsilon_{n}\right)\right\}
\end{aligned}
$$


where $\zeta$ is the sea surface elevation. $m$ and $n$ are arbitrary two wave components. $\bar{P}_{m n}$ and $\bar{Q}_{m n}$ are the sum-frequency QTFs. $P_{m n}$ and $Q_{m n}$ are the difference-frequency QTFs. $\varepsilon$ is the phase angle of the wave component.

\section{Fatigue Evaluation Method Based on S-N Curves}

The fatigue damage of the tower and mooring lines is calculated following the MinerPalmgren hypothesis. The damage increases linearly within each load cycle. The fatigue damage of the structures can be referred as:

$$
D=\sum_{j}^{N_{\text {total }}} \frac{n_{j}}{N_{j}}
$$

where $n_{j}$ is the number of cycles at the $j$ th stress range in the time history; $N_{\text {total }}$ is the number of stress ranges; $N_{j}$ is the number of cycles to failure at the $j$ th stress range, which is determined according to the $S-N$ curve of the structure.

In accordance with the recommended practice released by DNV for fatigue design of offshore steel structures including wind turbine's tower [34], a two-slope $S-N$ curve is selected to calculate the number of cycles to failure $(N)$ corresponding to a stress range $(\Delta \sigma)$, as denoted in Equation (13):

$$
\log N=\log \bar{a}-m \log \left[\Delta \sigma\left(\frac{t}{t_{r e f}}\right)^{k}\right]
$$

where $m$ is the Wöhler exponent; $t_{r e f}$ is the reference thickness of the tower; $t$ is the thickness of the steel-made structure. $k$ is the thickness exponent. The values of these parameters are given in Table 4.

Table 4. S-N curve parameters of the tower.

\begin{tabular}{ccccccc}
\hline \multicolumn{2}{c}{$\boldsymbol{N} \leq \mathbf{1 0 ^ { \mathbf { 7 } }}$ Cycles } & \multicolumn{2}{c}{$\boldsymbol{N} \geq \mathbf{1 0}^{\mathbf{7}}$ Cycles } & Fatigue Limit at $\mathbf{1 0}^{\mathbf{7}}$ Cycles & $\boldsymbol{k}$ & $\boldsymbol{t}_{\text {ref }}$ \\
\hline $\mathrm{m}$ & $\log \bar{a}$ & $\mathrm{~m}$ & $\log \bar{a}$ & $\mathrm{MPa}$ & {$[-]$} & {$[\mathrm{m}]$} \\
\hline 3.0 & 12.164 & 5.0 & 15.606 & 52.63 & 0.2 & 0.025 \\
\hline
\end{tabular}

\section{Design Load Cases}

The 15 MW FOWT with the AcitiveFloat concept is expected to operate in a site off the east coast of the US. According to the met-ocean data observed in the specific site [35], 13 load cases are defined to cover the normal operation and survival environmental conditions as listed in Table 5. The turbulent wind field of each load case is generated using the TurbSim based on the Kaimal spectrum. The NTM wind type denotes the normal turbulence model and the EWM means the extreme wind model. Load cases 12\# and 13\# are the 1-year and 50-year return period extreme conditions. The JONSWAP spectrum is used to the generated the wave kinematics of the irregular waves based on the Airy wave theory. It is noted that the wind turbine is operating for normal power production in cases $\# 1 \sim 11$. The wind turbine is parked in cases \#12 and \#13 since the wind speed exceeds the cut-out wind speed limit. 
Table 5. Design load cases.

\begin{tabular}{cccccc}
\hline Case \# & $\begin{array}{c}\text { Wind } \\
\text { Speed/(m/s) }\end{array}$ & Wind Type & $\begin{array}{c}\text { Significant Wave } \\
\text { Height }(\mathbf{m})\end{array}$ & $\begin{array}{c}\text { Spectral Peak } \\
\text { Period (s) }\end{array}$ & Probability \\
\hline 1 & 4 & NTM & 1.102 & 8.515 & $4.24 \%$ \\
2 & 6 & NTM & 1.179 & 8.310 & $8.91 \%$ \\
3 & 8 & NTM & 1.316 & 8.006 & $13.84 \%$ \\
4 & 10 & NTM & 1.537 & 7.651 & $17.32 \%$ \\
5 & 12 & NTM & 1.836 & 7.441 & $17.91 \%$ \\
6 & 14 & NTM & 2.188 & 7.461 & $15.35 \%$ \\
7 & 16 & NTM & 2.598 & 7.643 & $10.84 \%$ \\
8 & 18 & NTM & 3.061 & 8.047 & $6.22 \%$ \\
9 & 20 & NTM & 3.617 & 8.521 & $2.86 \%$ \\
10 & 22 & NTM & 4.027 & 8.987 & $1.99 \%$ \\
11 & 24 & NTM & 4.516 & 9.452 & $0.29 \%$ \\
12 & 40 & EWM1 & 9.686 & 11.307 & $0.16 \%$ \\
13 & 50 & EWM50 & 16.654 & 18.505 & $0.05 \%$ \\
\hline
\end{tabular}

\section{Results and Discussions}

\subsection{Wave Excitations of the Platform}

Based on the panel model of the ActiveFloat platform concept, a frequency-domain analysis is performed to examine the diffraction and radiation effects of the floater using AQWA. The first-order wave excitation forces and moments of the platform are obtained. Figure 4 presents the first-order hydrodynamic forces at 0 degree wave heading direction. It is found that the surge force achieves its peak $\left(11.42 \times 10^{6} \mathrm{~N} / \mathrm{m}\right)$ at around $0.58 \mathrm{rad} / \mathrm{s}$ corresponding to a period of $10.78 \mathrm{~s}$. Another relatively smaller peak $\left(7.64 \times 10^{6} \mathrm{~N} / \mathrm{m}\right)$ is achieved at $1.06 \mathrm{rad} / \mathrm{s}$ corresponding to a period of $5.93 \mathrm{~s}$. The heave force decreases and then increases before it falls again with increase of frequency. The heave responses are expected to be sensitive to low-frequency waves. The second peak with an amplitude of $6.64 \times 10^{6} \mathrm{~N} / \mathrm{m}$ is achieved at the frequency of $0.67 \mathrm{rad} / \mathrm{s}$ corresponding to the period of $9.39 \mathrm{~s}$. Those characteristic periods fall within the spectral peak period range of waves at the target site (see Table 5). This implies that the first-order surge and heave forces due to waves will be significant. The sway forces at all examined frequencies are relatively insignificant due to the bias of wave heading.
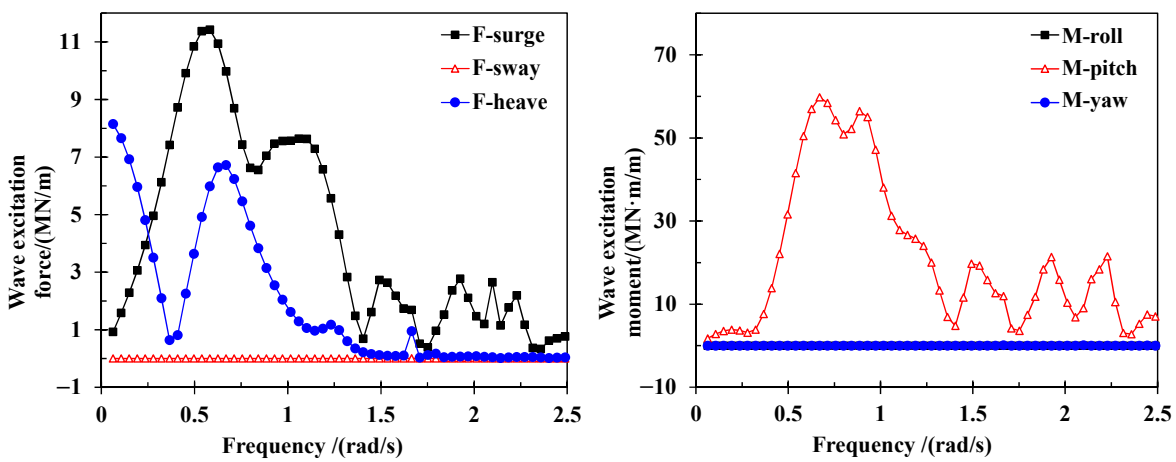

Figure 4. First-order wave excitation forces and moments at zero degree wave heading direction.

The pitch force has two peaks at frequencies of $0.67 \mathrm{rad} / \mathrm{s}$ and $0.89 \mathrm{rad} / \mathrm{s}$. The amplitudes are $59.80 \times 10^{6} \mathrm{~N} \cdot \mathrm{m} / \mathrm{m}$ and $56.44 \times 10^{6} \mathrm{~N} \cdot \mathrm{m} / \mathrm{m}$. The pitch force at each examined frequency is larger than the roll and yaw forces at the 0 degree wave heading, as expected.

The second-order hydrodynamic loads are relative to wave nonlinear effects and they are quadratic with the amplitudes of a pair of incident waves with several frequencies. The sum- and difference-frequency QTF matrices of the ActiveFloat platform at 0 degree are presented in Figure 5. As shown in Figure 5a, the difference-frequency surge, heave, and 
pitch QTF items have relatively larger values compared to the other three components. It is found that the maximum surge difference-frequency force is around $0.9 \times 10^{6} \mathrm{~N} / \mathrm{m}$ when a low-frequency wave is coupled with a high-frequency wave. For the most common wave frequency ranges, the difference-frequency surge force is around $0.1 \times 10^{6} \mathrm{~N} / \mathrm{m}$ that is close to $1 \%$ of the maximum first-order surge force. The difference-frequency heave and pitch forces have a relatively large value when a $0.67 \mathrm{rad} / \mathrm{s}$ wave component is combined with another $0.32 \mathrm{rad} / \mathrm{s}$ wave component. The maximum heave QTF item is around 3\% 8\% of the peak first-order heave force. The same phenomenon is observed for the pitch QTF item.

The sum-frequency QTF items are relatively larger than the difference-frequency items. The large surge and pitch QTF items are distributed in high frequency ranges. The heave QTF achieves its peak value when the frequency of the pair waves is around $0.32 \mathrm{rad} / \mathrm{s}$. The peak value is around 5\% of the maximum first-order heave force. Since the second-order wave forces are related to quadratic wave amplitudes, the contribution of second-order hydrodynamics will be significant in the waves with a large amplitude and high spectral peak period.

(a)
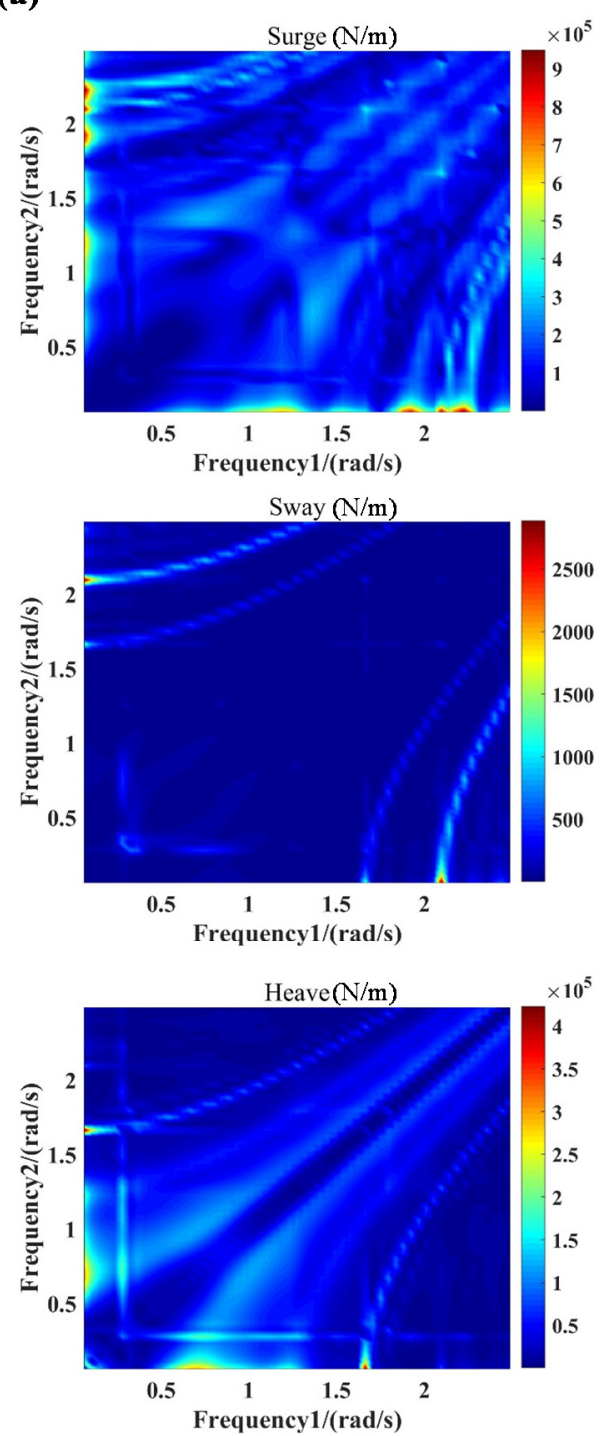
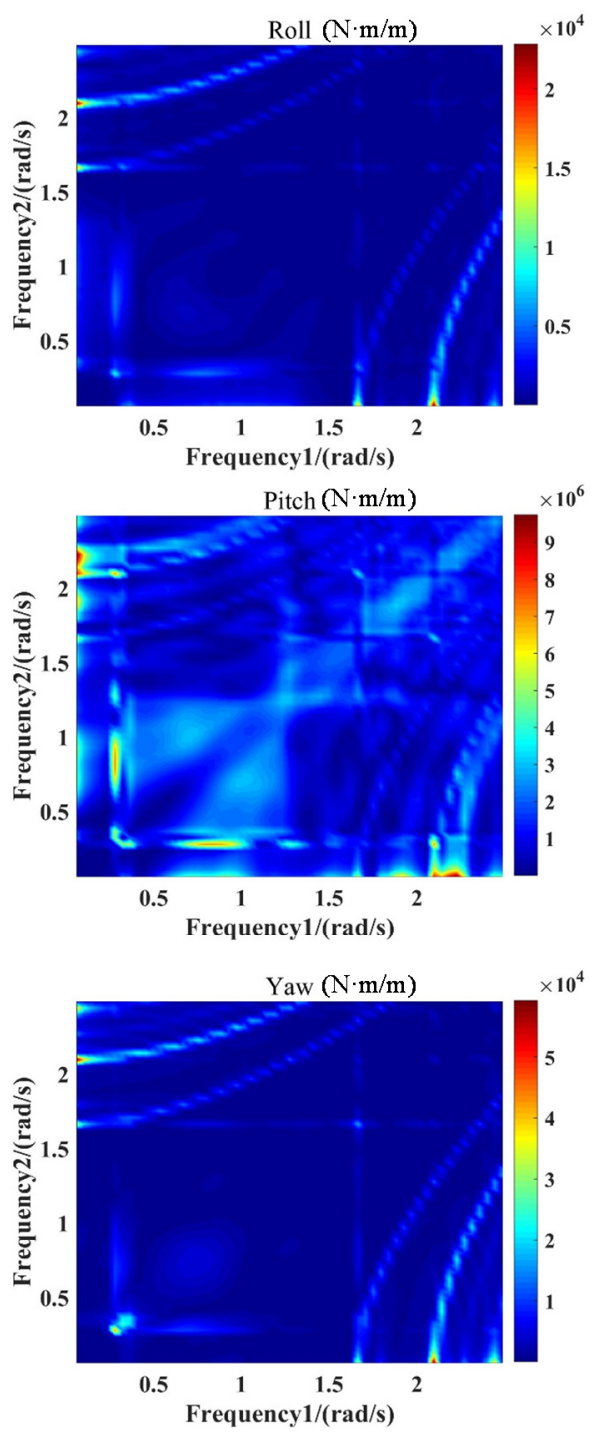

Figure 5. Cont. 
(b)
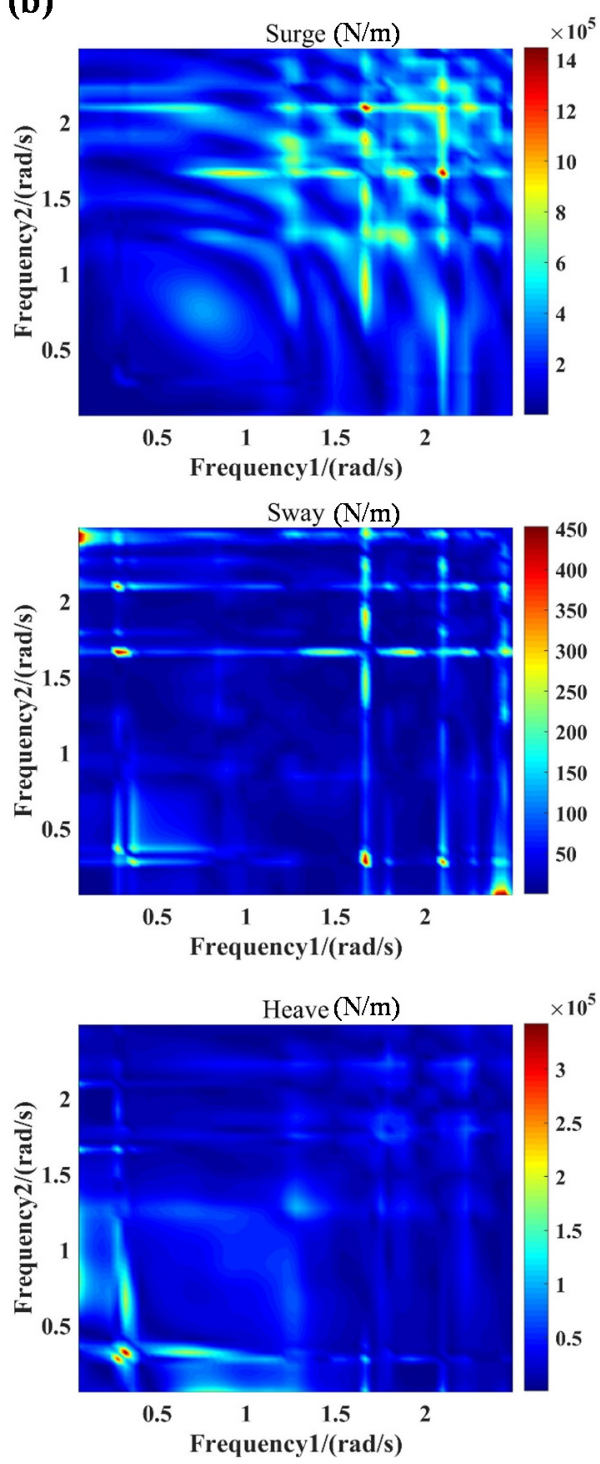
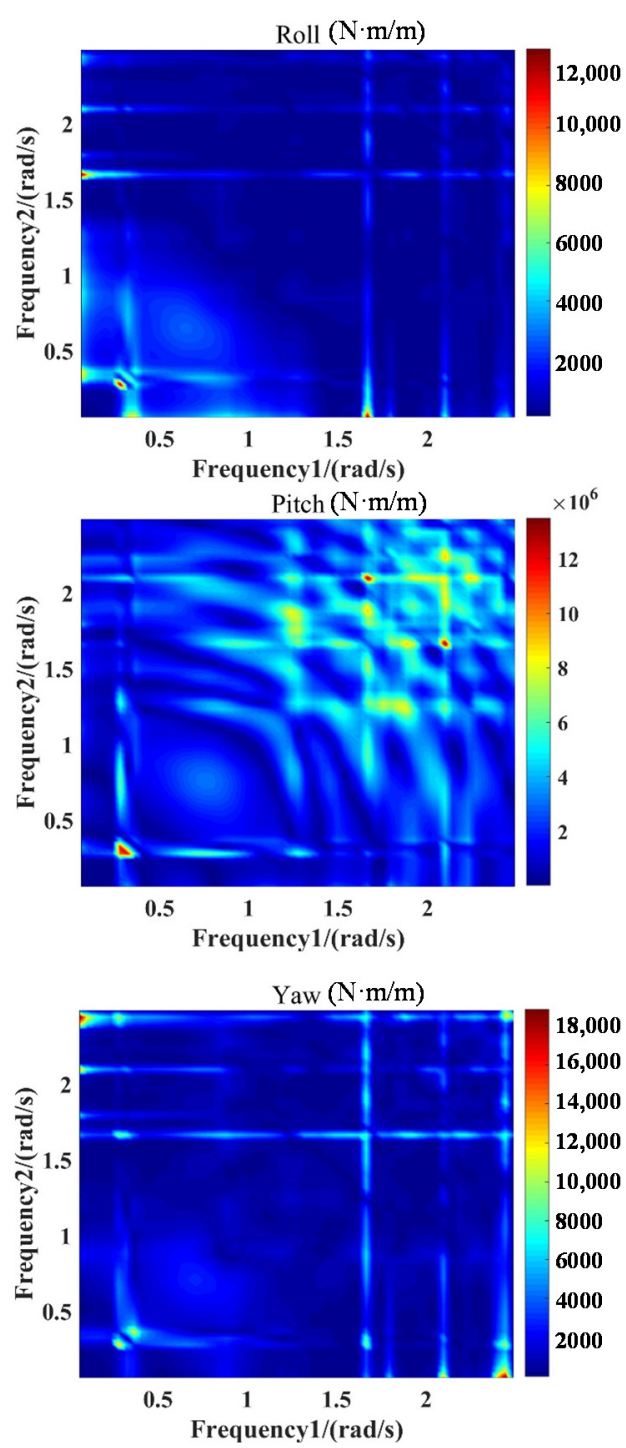

Figure 5. Second-order wave excitation forces and moments at zero degree wave heading direction: (a) difference-frequency, (b) sum-frequency.

\subsection{Dynamic Responses of the FOWT}

\subsubsection{Platform Motions}

The wave loading is aligned with the inflow direction of the wind. The sway and roll motions of the platform are insignificant compared to the surge and pitch motions. Thus, only the surge, heave, pitch, and yaw motions of the platform are analyzed in the following discussions. The statistics of the platform motions are calculated based on the time domain results within $500 \mathrm{~s} 1000 \mathrm{~s}$ to avoid the transient behavior influence in the beginning of the simulations. Figure 6 presents the maximum platform motions with and without considering the second-order hydrodynamics.

It is found that the second-order wave excitations have a notable effect on the surge motions. When the second-order hydrodynamics are examined, the maximum surge motion is larger than that due to the only first-order hydrodynamics for each load case. Nonetheless, the difference between the surge motions of the two loading scenarios is relatively small in load cases \#1 \#11. This is because the wind turbine is operating in the normal power production mode, thus the surge motion is dominated by the wind loading. However, the second-order hydrodynamic loads is a major contributor to the surge motions in unloaded cases \#12 \#13. For instance, the maximum surge motion is $4.06 \mathrm{~m}$ in load case 
\#12 when the second-order hydrodynamics are ignored, while the corresponding value is $5.82 \mathrm{~m}$ when the second-order hydrodynamics are taken into account. The major reason is that the wind turbine is under the parked mode. Consequently, the aerodynamic load is relatively small and the hydrodynamic loads take over the domination role of the platform results. Therefore, the effect of the second-order hydrodynamics is more significant.
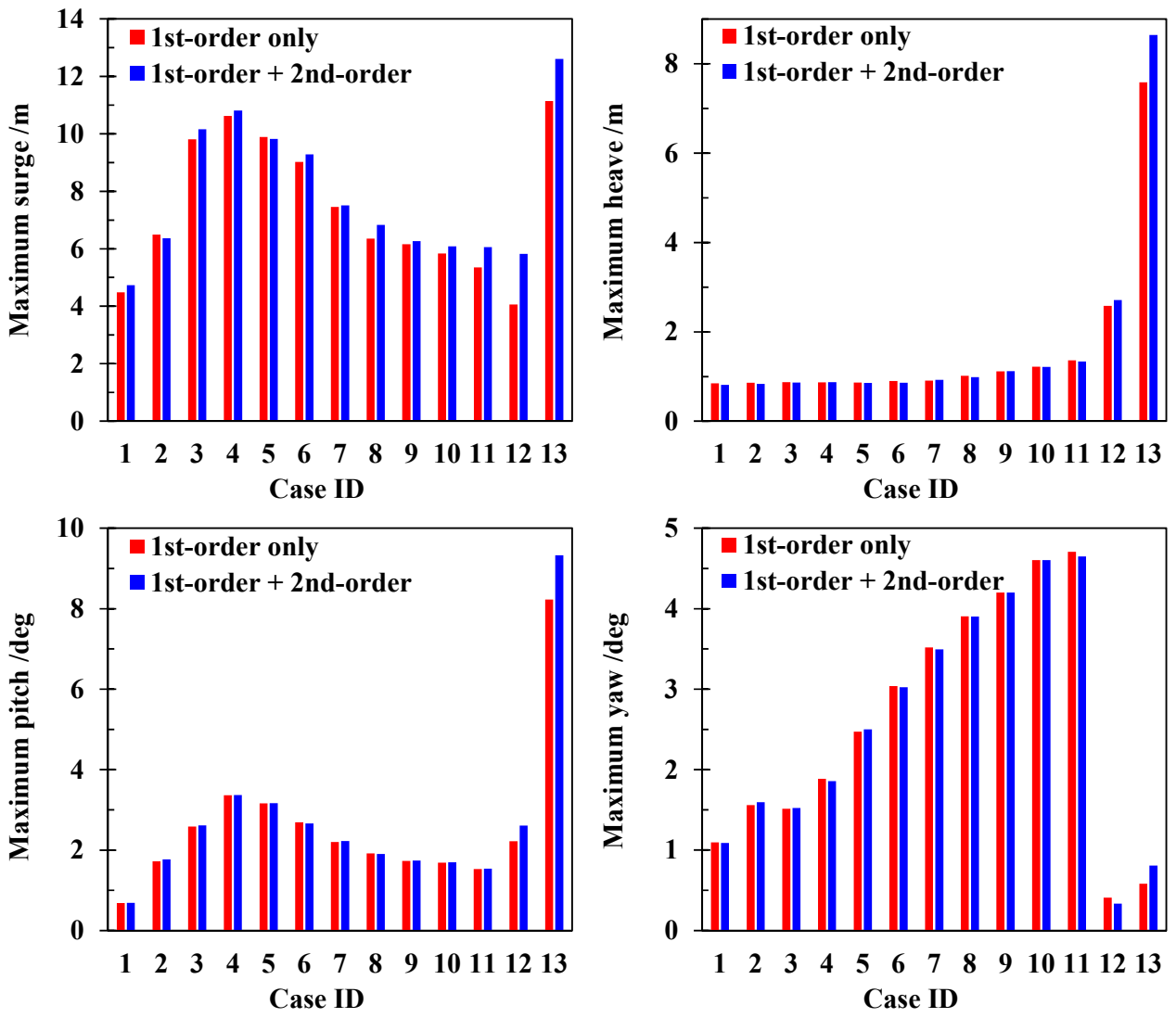

Figure 6. Maximum platform motions under all the examined load cases with and without considering the second-order wave excitations.

For both the heave and pitch motions with and without considering the second-order hydrodynamics, the difference between the results of the two loading scenarios is insignificant for each load case, since the aerodynamic load dominates the platform heave and pitch motions. Similar to the results of surge motions, the second-order hydrodynamics have a notable influence on the heave and pitch motions. When the second-order wave excitations are considered, the maximum heave and pitch motions are $8.64 \mathrm{~m}$ and 9.33 degrees, respectively, in load case \#13, while the corresponding values are $7.59 \mathrm{~m}$ and 8.23 degrees, respectively, when the second-order hydrodynamic loads are neglected. This means that the maximum heave and pitch motions are underestimated by $13.92 \%$ and $13.36 \%$, respectively, if only the first-order wave excitations are examined in the analysis.

It is observed that the maximum platform motions with an exception of the yaw motion under the extreme loadings are larger than those in the operational conditions, although the wind turbine is parked. The yaw motions are relatively smaller when the wind turbine is parked. This implies that the unbalanced loads on the platform driving the yaw motion are mainly produced by the aerodynamic loads. The hydrodynamic loads induce a relatively small yaw motion due to the symmetric geometry of the platform. Nonetheless, the second-order hydrodynamics increase the yaw motion by $39 \%$ in the extreme condition (load case \#13).

From the statistical analysis of the platform motions, it is found that the secondorder hydrodynamic loads play a relatively significantly role in contributing the platform 
motions. The time-varying motions of the platform under the extreme load case are presented in Figure 7.
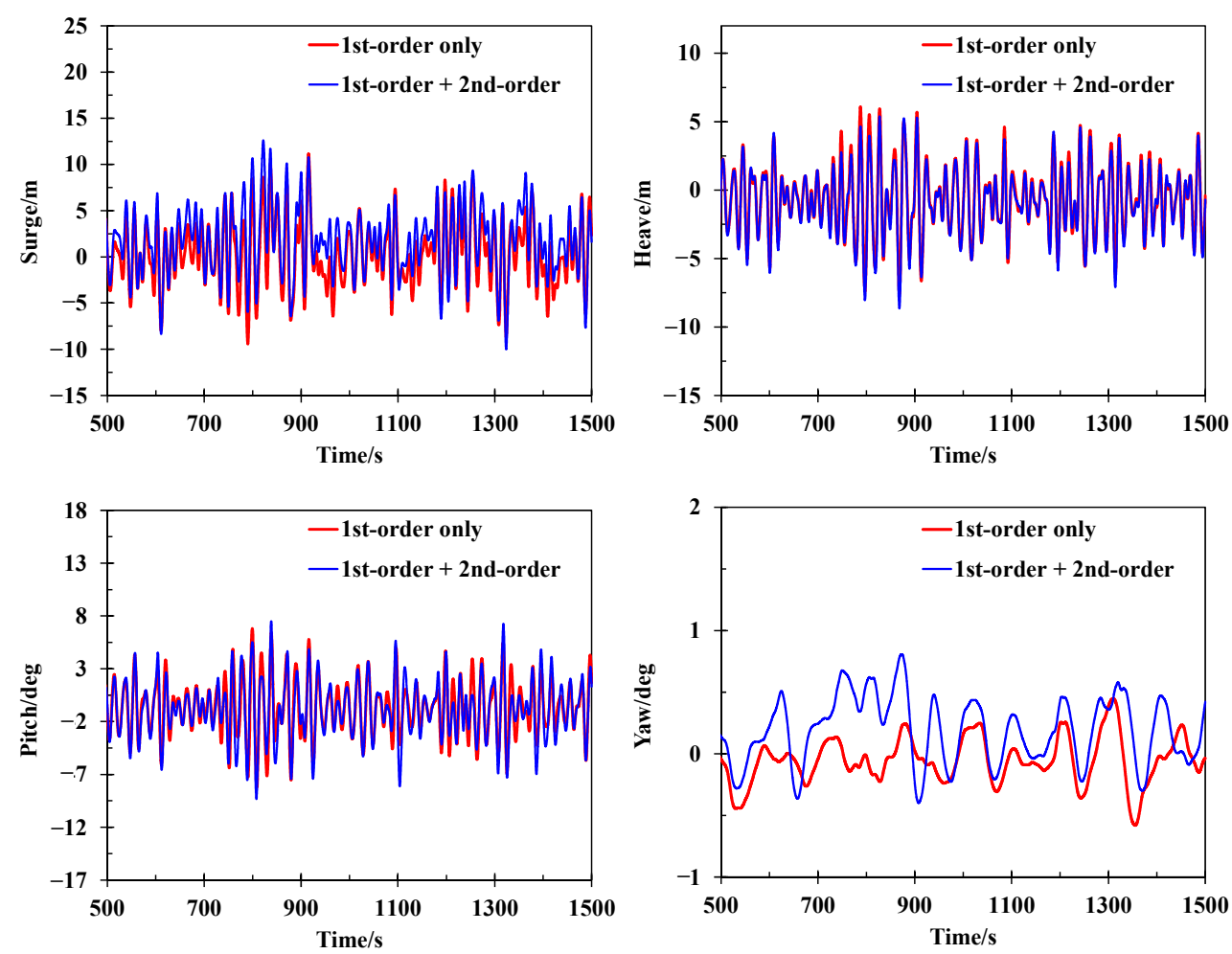

Figure 7. Time-varying platform motions under the extreme condition with and without considering the second-order wave excitations.

The spectral responses of the platform motions are obtained by applying the Fast Fourier Transformation (FFT). Figure 8 presents the spectra of the platform surge and yaw motions to illustrate the contributions of the second-order hydrodynamic loads. It is observed that the surge component of the mean hydrodynamic force is significantly increased due to the presence of second-order wave excitation, as confirmed by the larger amplitude at zero frequency. In addition, the surge mode is activated by the second-order hydrodynamic loads. The amplitude at the surge nature frequency is almost equivalent to that at the spectral peak frequency of the irregular wave $(0.054 \mathrm{~Hz})$. The spectra of heave and pitch motions indicate that the second-order hydrodynamics only enhances the mean force magnitude. The responses corresponding to the wave frequency are almost not affected by the involvement of second-order hydrodynamics. Due to the high magnitude of the yaw QTF items in low frequency area, the yaw amplitude is increased accordingly, especially at zero frequency. This implies that the mean yaw moment is much larger when considering the contribution of second-order loads.

\subsubsection{Tower-Base Loads}

At the tower-base, the bending moment consists of the contribution of aerodynamic forces and hydrodynamic loads. In order to analyze the effect of second-order hydrodynamics, Figure 9 presents the maximum bending moments at the tower-base under each examined load case, where I-P means the in-plane component and O-o-P denotes the out-of-plane component that is aligned with the wind-wave inflow direction. It is interesting to find that the second-order hydrodynamic loads increase the tower-base bending moments in some cases but also decrease the bending moments in the other cases when the wind turbine is operating for power production. This is because the hydrodynamic force is acting on the platform that is below the tower-base, while the aerodynamic loads are acting on the rotor above the tower-base. In some cases, the larger hydrodynamic 
loads decrease the bending moment when its induced bending moment is inverse to that cased by the aerodynamic thrust. In addition, due to the complex interaction between hydrodynamics, aerodynamics, and structural responses, the larger hydrodynamic loads with the contribution of second-order wave excitations are not expected to increase the bending moments at the tower base.
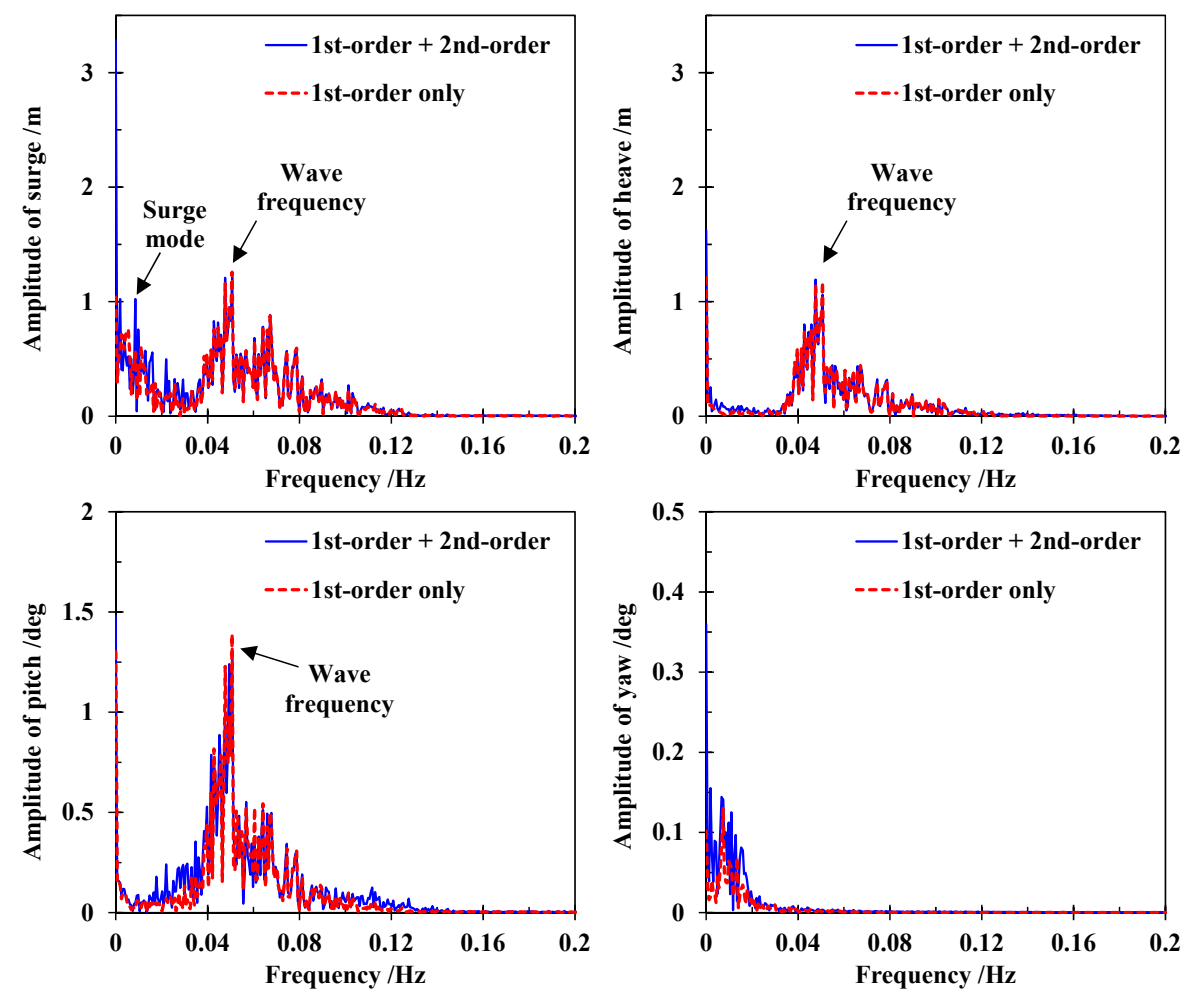

Figure 8. Spectral amplitudes of the platform motions under the extreme condition.
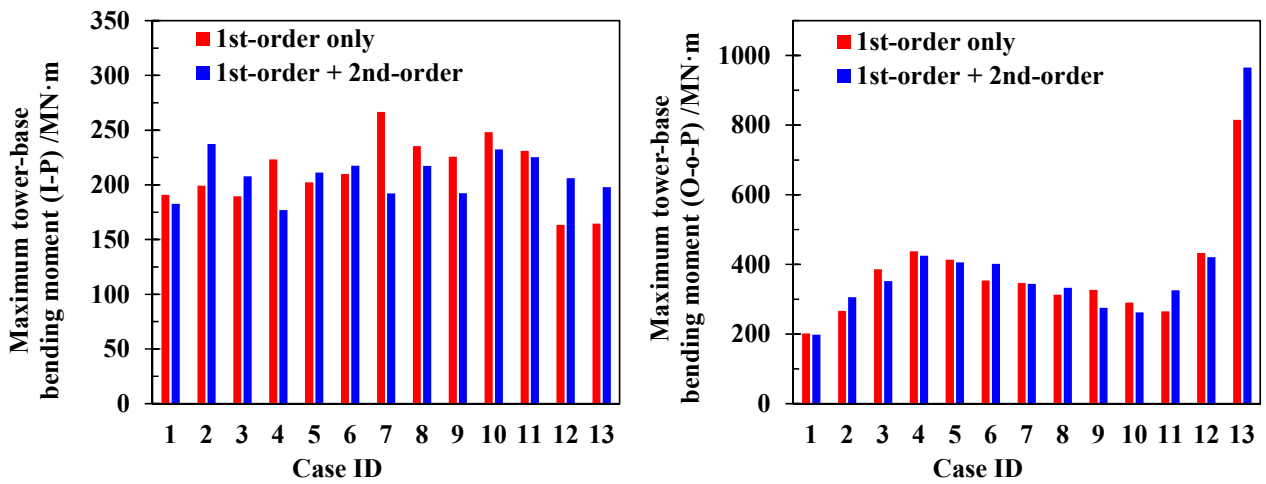

Figure 9. Maximum tower-base bending moments under all the examined load cases with and without considering the second-order wave excitations.

Nonetheless, the second-order wave loads significantly increase both of the in-plane and out-of-plane tower-base bending moments in the parked states, especially in the 50 -year return period extreme condition. In the unloaded case \#13, the maximum in-plane bending moments are, $197.9 \mathrm{MN} \cdot \mathrm{m}$ and $164.5 \mathrm{MN} \cdot \mathrm{m}$ with and without the contribution of second-order wave excitations, respectively. The corresponding values of the out-of-plane bending moments are $965.4 \mathrm{MN} \cdot \mathrm{m}$ and $814.9 \mathrm{MN} \cdot \mathrm{m}$, respectively. This means that the extreme bending moments at the tower-base are underestimated by around $20 \%$ if ignoring the second-order hydrodynamics. Therefore, the second-order wave excitations must be taken into account when performing the structural analysis of the FOWT. 
Figure 10 presents the mean value and standard deviation of the tower-base bending moments under each examined load case. It is found that the mean value of the in-plane bending moment at the tower-base increases gradually with the increase of wind speed when the wind turbine is generating electricity (load cases \#1 \#11). However, the standard deviation of the in-plane bending moment is similar for each examined load case. In unloaded cases \#12 \#13, the mean in-plane bending moment is a close zero and the presence of second-order hydrodynamics increases the fluctuation as indicated by the relatively larger standard deviation.
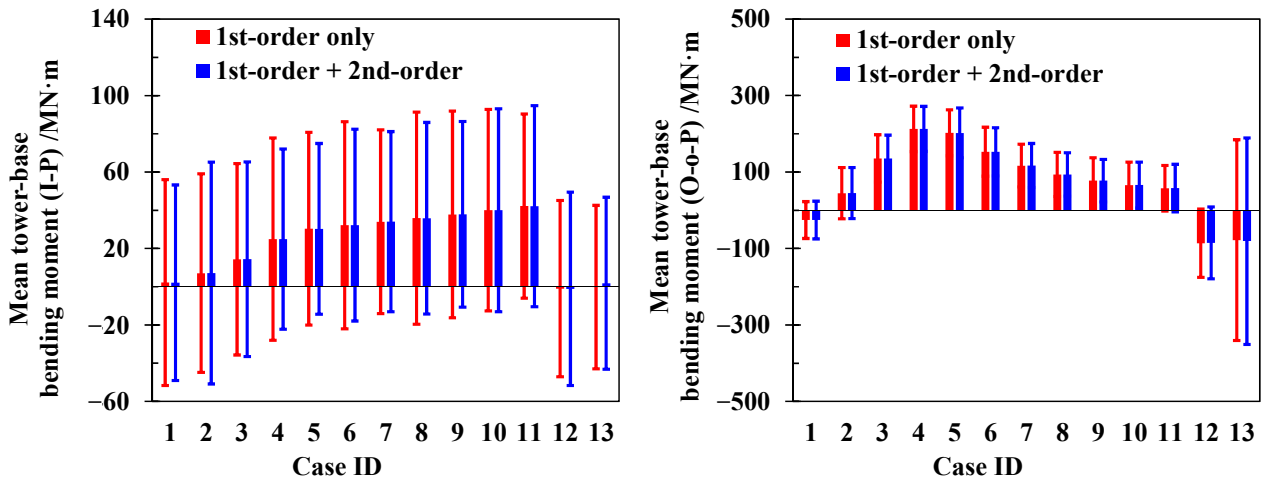

Figure 10. Mean values and standard deviations of the tower-base bending moment under all the examined load cases with and without considering the second-order wave excitations.

For the out-of-plane bending moment at the tower-base, the effect of the second-order hydrodynamics is slight as well. When the wind turbine is under the parked state, the mean out-of-plane bending moment is negative. This is because the rotor thrust produced by the wind is smaller than the force generated by the wave in the parked states. The platform is inclining to the wind due to the wave excitation. In addition, the standard deviation in the extreme condition is significantly larger than that in other power production cases. The presence of the second-order hydrodynamics has an insignificant effect on the out-of-plane tower-base bending moments. This implies that the first-order wave excitation is the major contributor to the tower-base bending moments.

Figure 11 presents the tower-base bending moments under unloaded case \#13 in which the met-ocean condition is defined in accordance with the 50-year return period rule. Since the wind turbine is under the parked state, in another word, the blades are pitching to the feathered state. The mean values of the bending moments are close to zero. Although the tower bending moments are not in line with each other due to the second-order wave excitations, the difference is relatively small. This means that the tower bending moments are slightly affected by the second-order hydrodynamics under the extreme condition.
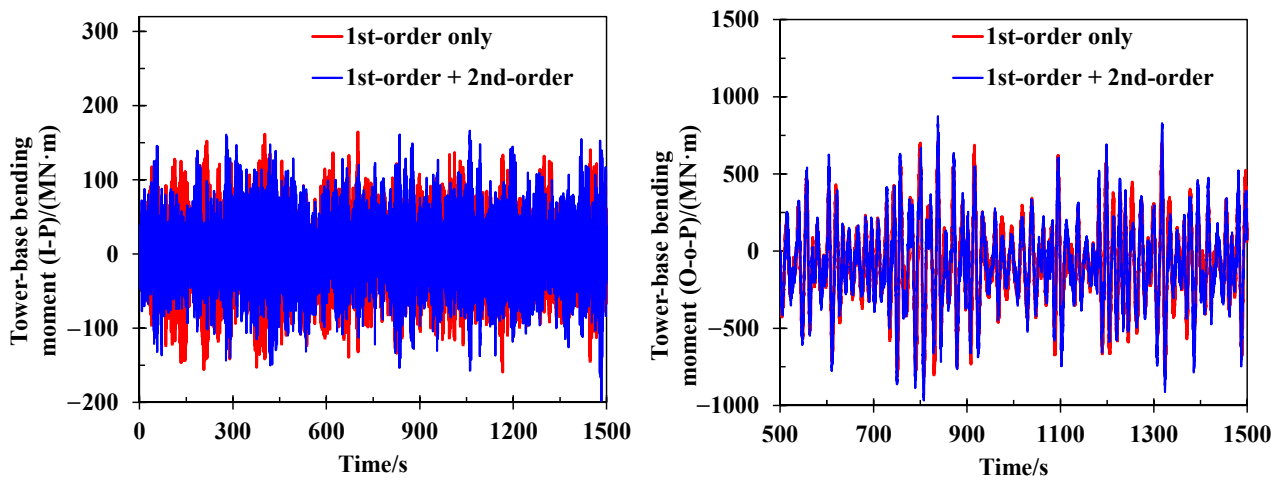

Figure 11. Time-varying tower-base bending moments under the extreme condition with and without considering the second-order wave excitations. 


\subsection{Fatigue Damage of the Tower}

It is known that the second-order wave excitations have a notable contribution to the tower loads. The maximum values of the tower-base bending moments are different when the second-order hydrodynamics are considered or not. It is expected that the fatigue damage at the tower-base is influenced by the second-order hydrodynamics.

The Miner method is used to evaluate the fatigue damage based on a two-slope S-N curve of the steel in accordance with the DNV standard. The thickness of the tower-base used in Equation (12) is $59 \mathrm{~mm}$. The stress $\sigma$ at the tower-base can be converted using the tower-base loads as follows:

$$
\sigma=\frac{F_{z}}{A}+\frac{M_{x}}{I_{x}} r \cos \theta+\frac{M_{y}}{I_{y}} r \sin \theta
$$

where $F_{z}, M_{x}$ and $M_{y}$ are, respectively, the vertical shear force, in-plane bending moment and out-of-plane bending moment at the tower base. $A, I_{x}$ and $I_{y}$ are respectively the local area and inertial areas at the tower-base. $r$ is the radius of the tower-base section. $\theta$ is the angle corresponding to the target point as illustrated in Figure 12.

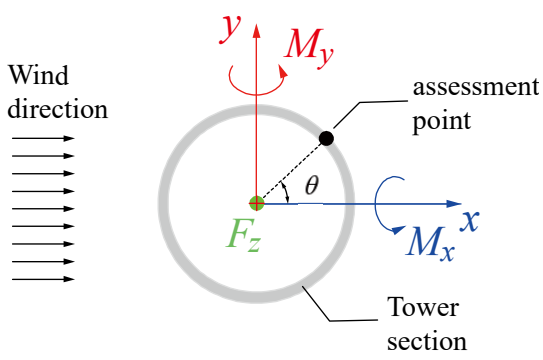

Figure 12. Coordinate system of the fatigue assessment point at the tower base.

Based on the simulation results, fatigue damage at different orientation angles of the tower-base is calculated in accordance with the DNV rules. Figure 13 presents the fatigue damage rates of the assessment points located at 0 degree and 90 degree for each examined load cases. For the 0 degree assessment point, the in-plane tower-base bending moment is the main contributor to the fatigue damage. The damage rate distribution over the load cases is similar to that of the maximum in-plane bending moment. It is found that the second-order hydrodynamics make a significant contribution to the fatigue damage in load case \#2 in which the wind speed is only $6 \mathrm{~m} / \mathrm{s}$. In load cases \#4 \#9, the presence of second-order wave excitations decreases the fatigue damage.
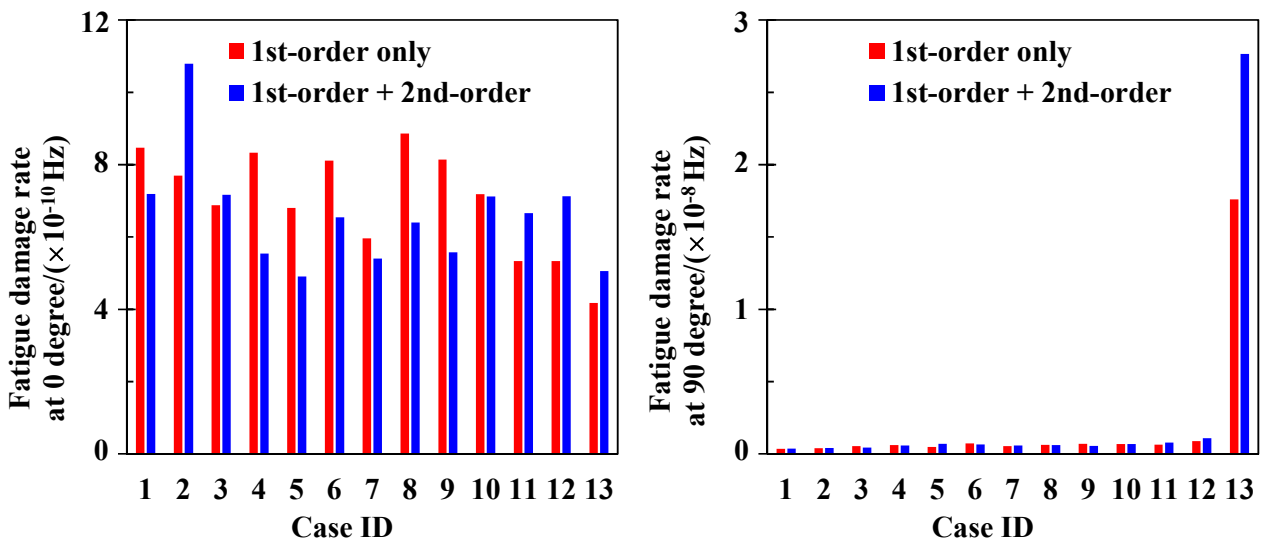

Figure 13. Fatigue damage rate at different tower-base locations of each load case.

The fatigue damage rate at the 90 degree assessment point under the extreme condition is much larger than that in other load cases, although the wind turbine is under 
the parked state. Due to the large fluctuation in the out-of-plane tower-base bending moment, the fatigue damage rate is around 100 times larger. In addition, the second-order hydrodynamics have a significant effect on the damage. More specifically, the damage rates are $2.77 \times 10^{-8}$ and $1.76 \times 10^{-8}$, respectively, for the cases with and without second-order hydrodynamic forces. This means that the fatigue damage of the tower-base under the extreme condition is underestimated by $57.1 \%$ if the effect of second-order hydrodynamics is ignored.

Considering the occurrence probability, the fatigue damage at different orientation angles of the tower-base over 25 years is predicted and presented in Figure 14. It is found that load cases \#3 \#6 are the major contributors to the overall damage at the tower-base for each assessment point. It is interesting to find that the damage is smaller if only the first-order wave excitations are considered. This implies that the structural strength design at the tower-base is relatively conservative if the second-order hydrodynamics are not considered in the fatigue analysis. Although the extreme wave condition produces a very large damage rate, the accumulative damage within 25 years caused by the extreme wave condition is less than 0.015 due to its low occurrence probability.
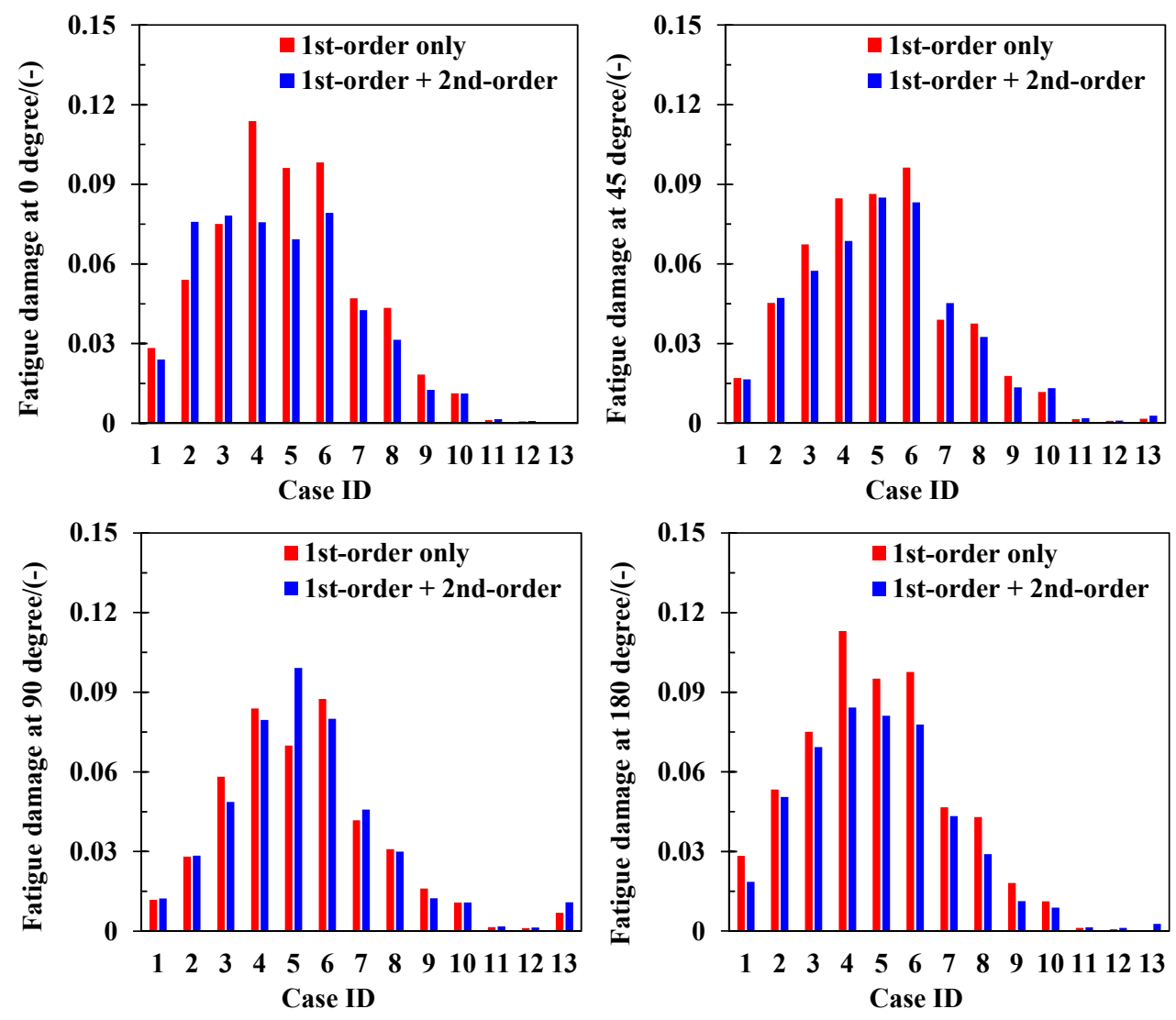

Figure 14. Fatigue damage at different tower-base locations of each load case over 25 years.

Table 6 presents the accumulative damage at different tower-base assessment points over 25 years. It is found that all the damage at each assessment point is smaller than 1.0, implying that the tower-base structural design meets the fatigue requirement. In addition, the fatigue damage is larger when ignoring the second-order hydrodynamic loads for almost all of the assessment points, with exceptions to $90^{\circ}$ and $270^{\circ}$. These two assessment points are located at the lateral side of the tower section. This means that second-order hydrodynamics enhance the in-plane bending moment at the tower-base. As a result, the fatigue damage is larger. However, for the remaining assessment points, the presence of second-order hydrodynamic loads reduces the fatigue of the tower-base. This indicates 
that the fatigue damage is overestimated if neglecting the second-order wave excitations. Consequently, the structural design is more conservative.

Table 6. Accumulative damage at different assessment points of the tower-base with and without second-order hydrodynamics.

\begin{tabular}{ccccccccc}
\hline & $\mathbf{0}^{\circ}$ & $\mathbf{4 5}^{\circ}$ & $\mathbf{9 0}^{\circ}$ & $\mathbf{1 3 5}^{\circ}$ & $\mathbf{1 8 0}^{\circ}$ & $\mathbf{2 2 5}^{\circ}$ & $\mathbf{2 7 0}^{\circ}$ & $\mathbf{3 1 5}^{\circ}$ \\
\hline Without second-order & 0.5880 & 0.5075 & 0.4484 & 0.5149 & 0.5836 & 0.5273 & 0.4753 & 0.5398 \\
With second-order & 0.5029 & 0.4682 & 0.4613 & 0.4794 & 0.4999 & 0.4863 & 0.4920 & 0.5053 \\
\hline
\end{tabular}

It is also found that the fatigue hotspot is at the $0^{\circ}$ and $180^{\circ}$ directions. In another word, the out-of-plane loads are the major contributor, no matter whether the second-order hydrodynamics are considered or not. Without the contribution of second-order wave excitations, the fatigue damage is overestimated by around $16.92 \%$, equivalent to a fatigue lifetime of 7.19 years. This implies that the second-order hydrodynamics on the platform must be considered in the tower structural design of the FOWT to reduce the cost.

\section{Conclusions}

This paper presents a study on the second-order hydrodynamics of a 15 MW FOWT. The effects of second-order hydrodynamic loads on the dynamic responses and fatigue damage at the tower base are evaluated quantitatively. The conclusions of this study are listed as follows:

(1) The sum- and difference-frequency QTFs of the $15 \mathrm{MW}$ floating wind platform are calculated for a wide-range of wave frequency. The maximum surge QTF item is around $1 \%$ of the first-order wave excitation force. The sum-frequency QTF items with large magnitude are distributed in large frequency ranges.

(2) The second-order hydrodynamics increase the maximum surge motions, since the surge mode is activated. The heave and pitch motions that are dominated by aerodynamic loads are slightly affected by the second-order excitations under power production cases. However, the extreme pitch and heave responses are enhanced due to the presence of second-order hydrodynamics. The maximum yaw motion is increased by $39 \%$ as well.

(3) The tower-base bending moments are considerably affected by the second-order hydrodynamics. Both of the in-plane and out-of-plane bending moments are decreased if neglecting the contribution of second-order hydrodynamic loads. Nonetheless, the first-order wave excitation is the major contributor to the tower-base bending moments.

(4) The fatigue damage rate at the 90 degree assessment point under the extreme condition is around 100 times larger than that in other load cases. The fatigue damage of the tower-base under the extreme condition is underestimated by $57.1 \%$ if the effect of second-order hydrodynamics is ignored.

(5) The accumulative damage of each assessment point at the tower-base is lower than 1.0, implying that the structural design has satisfied the basic requirement of fatigue. In addition, the fatigue damage is overestimated by around $16.92 \%$ without the contribution of second-order wave excitations. Therefore, the second-order hydrodynamics must be considered in the design of tower of a FOWT to reduce the cost.

Author Contributions: X.M.: conceptualization, methodology, software, validation, writing-original draft preparation, project administration, funding acquisition; M.X.: writing-review and editing, supervision; All authors have read and agreed to the published version of the manuscript.

Funding: This research was funded by the Shanghai Pujiang Program, grant number 2019PJD054.

Institutional Review Board Statement: Not applicable.

Informed Consent Statement: Not applicable. 
Data Availability Statement: All data generated or analysed during this study are included in this published article.

Acknowledgments: The authors are greatly grateful for the financial support from the Shanghai Pujiang Program (2019PJD054).

Conflicts of Interest: The authors declare no conflict of interest.

\section{References}

1. Global Wind Energy Council. Global Wind Report 2020; GWEC: Brussel, Belgium, 2021.

2. Det Norske Veritas and Germanischer Lloyd. The Energy Transition Outlook 2050; DNV-GL: Oslo, Norway, 2020.

3. Jiang, Z. Installation of offshore wind turbines: A technical review. Renew. Sust. Energ. Rev. 2021, 139, 110576. [CrossRef]

4. Robertson, A.; Jonkman, J.; Masciola, M.; Song, H.; Goupee, A.; Coulling, A.; Luan, C. Definition of the Semisubmersible Floating System for Phase II of OC4; National Renewable Energy Laboratory: Golden, CO, USA, 2014.

5. Robertson, A.N.; Jonkman, J.M.; Goupee, A.J.; Coulling, A.J.; Prowell, I.; Browning, J.; Masciola, M.D.; Molta, P. Summary of conclusions and recommendations drawn from the DeepCwind scaled floating offshore wind system test campaign. In Proceedings of the International Conference on Offshore Mechanics and Arctic Engineering, Nantes, France, 9-14 June 2013.

6. Masciola, M.; Robertson, A.; Jonkman, J.; Coulling, A.; Goupee, A. Assessment of the importance of mooring dynamics on the global response of the DeepCwind floating semisubmersible offshore wind turbine. In Proceedings of the International Offshore and Polar Engineering Conference, Anchorage, AK, USA, 30 June-5 July 2013.

7. Hall, M.; Goupee, A. Validation of a lumped-mass mooring line model with DeepCwind semisubmersible model test data. Ocean Eng. 2015, 104, 590-603. [CrossRef]

8. Coulling, A.J.; Goupee, A.J.; Robertson, A.N.; Jonkman, J.M.; Dagher, H.J. Validation of a FAST semi-submersible floating wind turbine numerical model with DeepCwind test data. J. Renew. Sustain. Energy 2013, 5, 023116. [CrossRef]

9. Tran, T.T.; Kim, D.H. The coupled dynamic response computation for a semi-submersible platform of floating offshore wind turbine. J. Wind Eng. Ind. Aerodyn. 2015, 147, 104-119. [CrossRef]

10. Kim, H.C.; Kim, M.H. Comparison of simulated platform dynamics in steady/dynamic winds and irregular waves for OC4 semi-submersible 5MW wind-turbine against DeepCwind model-test results. Ocean Syst. Eng. 2016, 6, 1-21. [CrossRef]

11. Huang, Y.; Zhuang, Y.; Wan, D. Hydrodynamic Study and Performance Analysis of the OC4-DeepCWind Platform by CFD Method. Int. J. Comput. Methods 2021, 18, 2050020. [CrossRef]

12. Liu, Z.; Fan, Y.; Wang, W.; Qian, G. Numerical study of a proposed semi-submersible floating platform with different numbers of offset columns based on the DeepCwind prototype for improving the wave-resistance ability. Appl. Sci. 2019, 9, 1255. [CrossRef]

13. Lee, D.C.; Na, S.K.; Kim, S.; Kim, C.W. Deterministic fatigue damage evaluation of semi-submersible platform for wind turbines using hydrodynamic-structure interaction analysis. Int. J. Precis. Eng. 2021, 16, 1-12.

14. Netzband, S.; Schulz, C.W.; Göttsche, U.; Ferreira, G.D.; Abdel, M.M. A panel method for floating offshore wind turbine simulations with fully integrated aero-and hydrodynamic modelling in time domain. Ship Technol. Res. 2018, 65, 123-136. [CrossRef]

15. Ishihara, T.; Zhang, S. Prediction of dynamic response of semi-submersible floating offshore wind turbine using augmented Morison's equation with frequency dependent hydrodynamic coefficients. Renew. Energy 2019, 131, 1186-1207. [CrossRef]

16. Bayati, I.; Jonkman, J.; Robertson, A.; Platt, A. The effects of second-order hydrodynamics on a semisubmersible floating offshore wind turbine. J. Phys. Conf. Ser. 2014, 524, 012094. [CrossRef]

17. Roald, L.; Jonkman, J.; Robertson, A.; Chokani, N. The effect of second-order hydrodynamics on floating offshore wind turbines. Energy Procedia 2013, 35, 253-264. [CrossRef]

18. Zhou, S.; Müller, K.; Li, C.; Xiao, Y.; Cheng, P.W. Global sensitivity study on the semisubmersible substructure of a floating wind turbine: Manufacturing cost, structural properties and hydrodynamics. Ocean Eng. 2021, 221, 108585. [CrossRef]

19. Pegalajar, J.A.; Bredmose, H. Reproduction of slow-drift motions of a floating wind turbine using second-order hydrodynamics and Operational Modal Analysis. Mar. Struct. 2019, 66, 178-196. [CrossRef]

20. Zhang, L.; Shi, W.; Karimirad, M.; Michailides, C.; Jiang, Z. Second-order hydrodynamic effects on the response of three semisubmersible floating offshore wind turbines. Ocean Eng. 2020, 207, 107371. [CrossRef]

21. Xu, K.; Gao, Z.; Moan, T. Effect of hydrodynamic load modelling on the response of floating wind turbines and its mooring system in small water depths. J. Phys. Conf. Ser. 2018, 1104, 012006. [CrossRef]

22. Zhao, Z.; Wang, W.; Shi, W.; Li, X. Effects of second-order hydrodynamics on an ultra-large semi-submersible floating offshore wind turbine. Structures 2020, 28, 2260-2275. [CrossRef]

23. Chuang, Z.; Liu, S.; Lu, Y. Influence of second order wave excitation loads on coupled response of an offshore floating wind turbine. Int. J. Nav. Archit. Ocean Eng. 2020, 12, 367-375. [CrossRef]

24. Simos, A.N.; Ruggeri, F.; Watai, R.A.; Souto-Iglesias, A.; Lopez, P.C. Slow-drift of a floating wind turbine: An assessment of frequency-domain methods based on model tests. Renew. Energy 2018, 116, 133-154. [CrossRef]

25. Cao, Q.; Xiao, L.; Guo, X.; Liu, M. Second-order responses of a conceptual semi-submersible $10 \mathrm{MW}$ wind turbine using full quadratic transfer functions. Renew. Energy 2020, 153, 653-668. [CrossRef]

26. Li, J.; Jiang, Y.; Tang, Y.; Qu, X.; Zhai, J. Effects of second-order difference-frequency wave forces on floating wind turbine under survival condition. Trans. Tianjin Univ. 2017, 23, 130-137. [CrossRef] 
27. Yang, Y.; Bashir, M.; Michailides, C.; Li, C.; Wang, J. Development and application of an aero-hydro-servo-elastic coupling framework for analysis of floating offshore wind turbines. Renew. Energy 2020, 161, 606-625. [CrossRef]

28. Yang, Y.; Bashir, M.; Wang, J.; Michailides, C.; Loughney, S.; Armin, M.; Li, C. Wind-wave coupling effects on the fatigue damage of tendons for a $10 \mathrm{MW}$ multi-body floating wind turbine. Ocean Eng. 2020, 217, 107909. [CrossRef]

29. Yang, Y.; Bashir, M.; Wang, J.; Yu, J.; Li, C. Performance evaluation of an integrated floating energy system based on coupled analysis. Energy Convers. Manage. 2020, 223, 113308. [CrossRef]

30. Li, D.; Lu, W.; Li, X.; Guo, X.X.; Li, J.; Duan, W.Y. Second-order resonant motions of a deep-draft semi-submersible under extreme irregular wave excitation. Ocean. Eng. 2020, 209, 107496. [CrossRef]

31. Pham, T.D.; Shin, H. The Effect of the second-order wave loads on drift motion of a semi-submersible floating offshore wind turbine. J. Mar. Sci. Eng. 2020, 8, 859. [CrossRef]

32. Pinkster, J.A. Mean and low frequency wave drifting forces on floating structures. Ocean. Eng. 1979, 6, 593-615. [CrossRef]

33. Newman, J.N.; Lee, C.H. Boundary-element methods in offshore structure analysis. J. Offshore Mech. Arct. Eng. 2002, 124, 81-89. [CrossRef]

34. Det Norske Veritas. DNV-RP-C203: Fatigue Design of Offshore Steel Structures; DNV: Oslo, Norway, 2013.

35. Stewart, G.M.; Robertson, A.; Jonkman, J.; Lackner, M.A. The creation of a comprehensive metocean data set for offshore wind turbine simulations. Wind. Energy 2016, 19, 1151-1159. [CrossRef] 